\title{
CrystEngComm
}

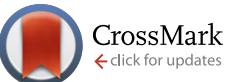

Cite this: CrystEngComm, 2016, 18, 1809

Received 20th November 2015 Accepted 22nd January 2016

DOI: $10.1039 / c 5 c e 02264 a$

www.rsc.org/crystengcomm

\section{Strong luminescent copper(I) halide coordination polymers and dinuclear complexes with thioacetamide and $\mathrm{N}, \mathrm{N}^{\prime}$-donor ligands $\uparrow$}

\author{
Javier Troyano, ${ }^{a}$ Josefina Perles, ${ }^{\text {b }}$ Pilar Amo-Ochoa, ${ }^{a}$ Félix Zamora*ac and \\ Salomé Delgado*a
}

\begin{abstract}
Direct reactions between copper(I) halides, thioacetamide (TAA) and 4,4'-bipyridine (4,4'-bpy) or pyrazine (pyz) in $\mathrm{MeCN}$ led to the formation of mixed ligand compounds $\left[\mathrm{Cu}_{2} \mathrm{Cl}_{2}(\mathrm{TAA})_{2}\left(4,4^{\prime}-\mathrm{bpy}\right)\right]_{n}$ (1), $\left[\mathrm{Cu}_{2} \mathrm{X}_{2}(\mathrm{TAA})_{4}\left(4,4^{\prime}-\mathrm{bpy}\right)\right] \cdot\left(4,4^{\prime}-\mathrm{bpy}\right)\left(\mathrm{X}=\mathrm{Cl}(2), \mathrm{Br}(3)\right.$ and I (4)) and $\left[\mathrm{Cu}_{2} \mathrm{Cl}_{2}(\mathrm{TAA})_{2}(\mathrm{pyz})\right]_{n}$ (5), and the binuclear complex $\left[\mathrm{Cu}_{2} \mathrm{I}_{2}(\mathrm{TAA})_{4}\right]$ (6). The formation of these compounds strongly depends on both the ratio of the reactants and the halide. The structures of these compounds have been determined by X-ray diffraction showing interesting intermolecular interactions based on hydrogen bonding. The physical properties of these compounds show that 1-5 are strongly luminescent with red emission (500-750 nm) at room temperature in the solid state, while compound 1 behaves as a semiconductor and 5 as an insulator.
\end{abstract}

\section{Introduction}

Coordination polymers (CPs) have attracted increasing attention in recent years due to their interesting architectures and physico-chemical properties. ${ }^{1}$ In particular, those with $\mathrm{Cu}(\mathrm{I})$ are relevant because of their structural diversity, electrical conductivity $^{2-5}$ and luminescence properties. ${ }^{6-8}$ Among these systems, $\mathrm{Cu}(\mathrm{I})$ halides represent a versatile type of building blocks that have been successfully used for the synthesis of CPs in combination with different neutral ligands., ${ }^{2,3,-11}$ Much effort has been devoted to the judicious selection of ligands in the construction of novel functional materials since they play an important role in tuning the final architecture of the products, and their physico-chemical properties. ${ }^{12}$ Additionally, the selection of the halide ${ }^{13}$ and/or the metal-toligand stoichiometry ${ }^{14}$ may affect both the final structure and properties of the CPs. In this context, it is well-known that $N$, $N^{\prime}$-ditopic ligands are able to generate coordination networks with fascinating supramolecular structures, which can be extended by combining one or several of these organizing

\footnotetext{
${ }^{a}$ Departamento de Química Inorgánica and Condensed Matter Physics Center (IFIMAC), Universidad Autónoma de Madrid, E-28049 Madrid, Spain. E-mail: felix.zamora@uam.es, salome.delgado@uam.es

${ }^{b}$ Servicio Interdepartamental de Investigación, Laboratorio de Difracción de Rayos X de Monocristal, Universidad Autónoma de Madrid, E-28049 Madrid, Spain

${ }^{c}$ Instituto Madrileño de Estudios Avanzados en Nanociencia (IMDEA

Nanociencia), Cantoblanco, 28049 Madrid, Spain

$\dagger$ Electronic supplementary information (ESI) available: Additional experimental data and CIF files. CCDC 1427905-1427910. For ESI and crystallographic data in CIF or other electronic format see DOI: 10.1039/c5ce02264a
}

forces: coordination bonds, hydrogen bonds and/or $\pi-\pi$ stacking interactions. ${ }^{15-17}$ This kind of ligand has a strong coordination ability through the nitrogen atoms, and can act as rigid-linear linkers between metal ions ${ }^{18-27}$ or as multitopic donor building blocks for the construction of more intriguing networks that include 1D, 2D and 3D coordination polymers. ${ }^{28-30}$ Additionally, aromatic nitrogen-donor ligands can improve the photoluminescence properties of $\mathrm{Cu}(\mathrm{I})$ halides. ${ }^{31-34}$ On the other hand, organosulfur-containing ligands have demonstrated their potential as linkers in the synthesis of metal-organic networks showing interesting electrical and luminescence properties. ${ }^{35}$ In particular, it has been observed that the incorporation of thiolate-S bridging ligands between adjacent transition-metal centres is highly desirable in terms of magnetic, electrical and optical properties. This is due to the fact that the metal orbital energies are better matched for sulphur, leading to a higher delocalization of the spin/charge density through the bridging atoms. We have reported multifunctional CPs based on $\mathrm{Cu}(\mathrm{I})$ and $\mathrm{S}$, N-ligands such as pyrimidinedisulfide, 2-dipyridyldisulfide and thioacetamide, showing luminescence emission and electrical conductivity. ${ }^{4,53}$ It seems that CPs based on a combination of mixed ligands ${ }^{37}$ enhance the structural diversity, and may produce some remarkable physical properties compared to the ones obtained using only one type of ligand. ${ }^{38-40}$ However, design and structure prediction still remains a challenge. Despite the fact that there are some examples of $\mathrm{Cu}(\mathrm{I})$ halide coordination polymers based on ligands which contain at the same time hard $\mathrm{N}$ and soft $\mathrm{S}$ donor atoms, ${ }^{5,41-45}$ or organosulfur ligands and acetonitrile, ${ }^{46,47}$ to the best of our knowledge, the combination of organosulfur and 
$\mathrm{N}$-heteroaromatic ligands to obtain $\mathrm{Cu}(\mathrm{I})$ halide coordination polymers still remains unexplored. Introduction of $N, N^{\prime}$ ditopic ligands, such as $4,4^{\prime}$-bipyridine and pyrazine, to the CuX-thioacetamide system might lead to new compounds with intriguing structures and improved electrical and luminescence properties. Due to competition between both kinds of ligands in the reaction mixture, it is possible in principle to tune the system depending on their ratio. ${ }^{48}$

In this work, we have investigated the coordination chemistry of copper complexes involving copper(I) halides, thioacetamide and 4,4'-bipyridine or pyrazine with the aim to produce multifunctional materials with electrical conductivity and photoluminescence.

\section{Results and discussion}

\section{Synthesis}

Mixed ligand compounds $\mathbf{1 - 5}$ were synthesized in acetonitrile at room temperature on air, as shown in Scheme 1.

Direct reactions between $\mathrm{CuX}(\mathrm{X}=\mathrm{Cl}, \mathrm{Br}, \mathrm{I})$, TAA and 4, $4^{\prime}$ bpy were carried out in acetonitrile in a $2: 2: 1$ stoichiometry, resulting in the formation of microcrystalline solids that were characterized by FT-IR, elemental analysis and X-ray powder diffraction (Fig. S1-S6†). The results revealed that when the reaction was carried out with $\mathrm{CuCl}$, the mixed ligand coordination polymer $\left[\mathrm{Cu}_{2} \mathrm{Cl}_{2}(\mathrm{TAA})_{2}\left(4,4^{\prime}-\mathrm{bpy}\right)\right]_{n} \mathbf{1}$, was formed. However, the analogous reactions carried out with $\mathrm{CuX}(\mathrm{X}=\mathrm{Br}, \mathrm{I})$ yielded the previously reported coordination polymers $\left[\mathrm{CuX}\left(4,4^{\prime} \text {-bpy }\right)\right]_{n}{ }^{10,14,17}$ The lack of thioacetamide observed in these compounds prompted us to test reactions by increasing the TAA: 4,4'-bpy ratio. Table 1 shows that the reactions tested in a $2: 4: 1$ stoichiometry gave rise to the formation of the same compounds, while when the reactions were carried out in a larger excess, a 2:8:1 ratio, the dinuclear complexes $\left[\mathrm{Cu}_{2} \mathrm{X}_{2}(\mathrm{TAA})_{4}\left(4,4^{\prime}\right.\right.$-bpy) $] \cdot\left(4,4^{\prime}\right.$-bpy $)(\mathrm{X}=\mathrm{Cl}(2), \mathrm{Br}(3)$ and $\mathrm{I}(4))$ were synthesized. Unfortunately, in the cases of $\mathrm{CuBr}$ and $\mathrm{CuI}$, we were unable to isolate mixed ligand polymers analogous to 1 and only rich thioacetamide complexes 2-4 were obtained by increasing the TAA : 4,4'-bpy ratio.

Reactions with pyrazine in a CuX:TAA: pyz 2:2:1 stoichiometry led to $[\mathrm{CuCl}(\mathrm{TAA})]_{3}$ and $[\mathrm{CuBr}(\mathrm{TAA})]_{n}$, containing only thioacetamide as the coordinating ligand, for $\mathrm{CuCl}$ and $\mathrm{CuBr}$, respectively, while $\left[\mathrm{Cu}_{2} \mathrm{I}_{2}(\mathrm{pyz})\right]_{n}$ for $\mathrm{CuI}^{10,46}$ The $[\mathrm{CuX}(\mathrm{TAA})]$ $(\mathrm{X}=\mathrm{Cl}, \mathrm{Br})$ compounds have been previously reported from

$$
2 \mathrm{CuCl}+2
$$

Scheme 1 Synthesis of mixed ligand compounds 1-5.
Table 1 Compounds obtained from the direct reactions between $\mathrm{CuX}(\mathrm{X}=$

\begin{tabular}{|c|c|c|c|}
\hline & $2: 2: 1$ & $2: 4: 1$ & $2: 8: 1$ \\
\hline $\mathrm{CuCl}$ & $1^{a}$ & $1^{a}$ & $2^{a}$ \\
\hline $\mathrm{CuBr}$ & $\begin{array}{l}{\left[\mathrm{CuBr}\left(4,4^{\prime}-\mathrm{bpy}\right)\right]_{n}} \\
\text { (ref. } 14 \text { and } 17)\end{array}$ & $\begin{array}{l}{\left[\mathrm{CuBr}\left(4,4^{\prime}-\mathrm{bpy}\right)\right]_{n}} \\
\text { (ref. } 14 \text { and } 17)\end{array}$ & $3^{a}$ \\
\hline $\mathrm{CuI}$ & $\begin{array}{l}{\left[\mathrm{CuI}\left(4,4^{\prime}-\text {-bpy }\right)\right]_{n}} \\
(\text { ref. } 10 \text { and } 17)\end{array}$ & $\begin{array}{l}{\left[\mathrm{CuI}\left(4,4^{\prime}-\mathrm{bpy}\right)\right]_{n}} \\
\text { (ref. } 10 \text { and } 17)\end{array}$ & $4^{a}$ \\
\hline
\end{tabular}
$\mathrm{Cl}, \mathrm{Br}, \mathrm{I}), \mathrm{TAA}$ and $4,4^{\prime}$-bpy in acetonitrile using different CuX:TAA : 4,4'-bpy ratios

${ }^{a}$ This work.

the direct synthesis between copper(I) or copper(II) halides and $\mathrm{TAA}^{36,49}$ (Table 2). In order to obtain mixed ligand compounds containing both TAA and pyz as ligands, we followed the same strategy as that used for the $4,4^{\prime}$-bpy derivatives. Thus, in the cases of $\mathrm{CuCl}$ and $\mathrm{CuBr}$, reactions wherein the pyz : TAA ratio was increased were tested (Table 2). For $\mathrm{CuCl}$, when using a 1:1:10 stoichiometry, the coordination polymer $\left[\mathrm{Cu}_{2} \mathrm{Cl}_{2}(\mathrm{TAA})_{2}(\mathrm{pyz})\right]_{n}$ (5) was isolated as a pure solid, while mixtures of $[\mathrm{CuCl}(\mathrm{TAA})]_{3}$ and 5 were obtained when using a lower ratio of TAA. The reactions between $\mathrm{CuBr}$ and thioacetamide in the presence of an excess of pyrazine yielded known coordination polymers $\left[\mathrm{Cu}_{2} \mathrm{Br}_{2} \text { (pyz) }\right]_{n}$ (ref. 50) and $[\mathrm{CuBr}(\mathrm{pyz})]_{n}$ (ref. 9), depending on the ratio of pyz. In contrast, in the case of CuI, only the dinuclear complex $\left[\mathrm{Cu}_{2} \mathrm{I}_{2}(\mathrm{TAA})_{4}\right]$ (6) was isolated at higher ratios of thioacetamide (Table 2).

\section{Solution studies}

The stability in solution of the mixed ligand compounds 1-5 was also investigated. In the experiments, acetonitrile suspensions of 1-5 were allowed to stand undisturbed for one day. Finally, the products were identified by X-ray powder diffraction. In all the experiments, with the exception of compound 1, a transformation takes place. Thus, for 2-4 the loss of thioacetamide and the subsequent formation of 1 together with $\left[\mathrm{CuX}\left(4,4^{\prime} \text {-bpy }\right)\right]_{n}(\mathrm{X}=\mathrm{Br}, \mathrm{I})^{10,14,17}$ were observed. The same procedure was employed for 5 , but in this case the release of pyrazine and the formation of $[\mathrm{CuCl}(\mathrm{TAA})]_{3}$ (ref. 49) took place (Scheme 2).

Taking into account these results, the formation and the stability in solution of compounds 1-5 seem to be governed by the competition between TAA and the $N, N^{\prime}$-ditopic ligands.

\begin{tabular}{|c|c|c|c|c|}
\hline & $2: 4: 1$ & $2: 2: 1$ & $1: 1: 2$ & $1: 1: 10$ \\
\hline $\mathrm{CuCl}$ & - & $\begin{array}{l}{[\mathrm{CuCl}(\mathrm{TAA})]_{3}} \\
\text { (ref. 49) }\end{array}$ & {$[\mathrm{CuCl}(\mathrm{TAA})]_{3}$} & $5^{a}$ \\
\hline $\mathrm{CuBr}$ & - & $\begin{array}{l}{[\mathrm{CuBr}(\mathrm{TAA})]_{n}} \\
\text { (ref. 36) }\end{array}$ & $\begin{array}{l}{\left[\mathrm{Cu}_{2} \mathrm{Br}_{2}(\mathrm{pyz})\right]_{n}} \\
\text { (ref. 50) }\end{array}$ & $\begin{array}{l}{[\mathrm{CuBr}(\mathrm{pyz})]_{n}} \\
\text { (ref. 9) }\end{array}$ \\
\hline CuI & $6^{a}$ & $\begin{array}{l}{\left[\mathrm{Cu}_{2} \mathrm{I}_{2}(\mathrm{pyz})\right]_{n}} \\
(\text { ref. } 10 \text { and } 51)\end{array}$ & - & - \\
\hline
\end{tabular}

Table 2 Compounds obtained from the direct reactions between $\mathrm{CuX}(\mathrm{X}=$ $\mathrm{Cl}, \mathrm{Br}, \mathrm{I}), \mathrm{TAA}$ and pyz in acetonitrile using different $\mathrm{CuX}$ : TAA : pyz ratios 
$\left[\mathrm{Cu}_{2} \mathrm{Cl}_{2}(\mathrm{TAA})_{4}\left(4,4^{\prime}-\right.\right.$-bpy $\left.)\right] \cdot\left(4,4^{\prime}-\right.$-bpy $)$ (2)

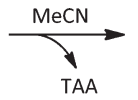

$\left[\mathrm{Cu}_{2} \mathrm{Cl}_{2}\left(\mathrm{TAA}_{2}\left(4,4^{\prime}-\mathrm{bpy}\right)\right]_{n}\right.$

(1)

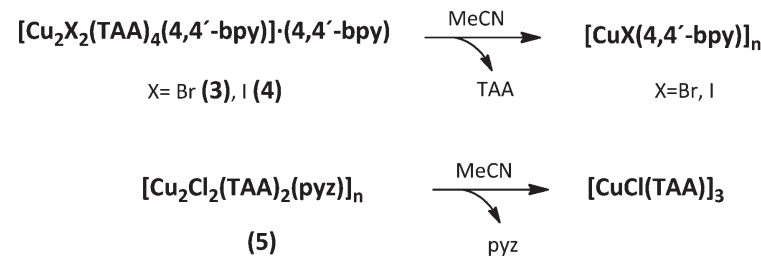

Scheme 2 Mixed ligand compounds 1-5 transformations after $24 \mathrm{~h}$ in acetonitrile.

Therefore, the synthesis of the mixed ligand compounds can only be achieved by controlling the ligand ratio. Once the complexes are formed, the suspension of these solids in acetonitrile implies a transformation because the ratio required for the stabilization is not reached. The stoichiometry employed for the synthesis corresponds to the final product composition only for $\mathbf{1}$, and no transformation occurs in solution.

\section{Description of crystal structures}

The crystal structures of compounds 1-6 were solved by single crystal X-ray diffraction. Complete data collection and refinement information are collected in the ESI, $\dagger$ and Fig. S7$\mathrm{S} 12 \dagger$ depict the asymmetric units with atoms labelled for compounds 1-6, respectively. The bond distances and angles for compounds 1-6 (Table 3) were found to be within the expected ranges and similar to the values presented by other similar compounds previously published. ${ }^{17,34,36}$

Compound 1 crystallizes in the monoclinic $P 2_{1} / c$ space group. The asymmetric unit consists of one copper(I) atom, one TAA, one chlorine and one half of a 4,4'-bpy ligand, to give the formula $\left[\mathrm{Cu}_{2} \mathrm{Cl}_{2}(\mathrm{TAA})_{2}\left(4,4^{\prime}-\mathrm{bpy}\right)\right]_{n}$. The copper centre is coordinated to two sulphur atoms from TAA fragments, a chlorine terminal ligand and a nitrogen from the 4,4'-bpy ligand in a tetrahedral $\mathrm{CuS}_{2} \mathrm{ClN}$ geometry. Both the TAA and 4, $4^{\prime}$-bpy ligands act as ditopic $\mu_{2}$ bridging ligands to yield a 2D polymeric structure with zigzag layers stacked by the $\mathrm{N}-$ $\mathrm{H} \cdots \mathrm{Cl}$ hydrogen bonds in the [100] direction, as is depicted in Fig. 1 and S13. $\dagger$ The distance between copper atoms is $4.025 \AA$ in the [001] direction (the atoms joined by sulphur atoms from the TAA ligands), and $11.252 \AA$ for centres bridged by the full length of the $4,4^{\prime}$-bpy ligands.

Compound 2 crystallizes in the triclinic $P \overline{1}$ space group. Its structure consists of $\left[\mathrm{Cu}_{2} \mathrm{Cl}_{2}(\mathrm{TAA})_{4}\left(4,4^{\prime}\right.\right.$-bpy) $]$ bimetallic molecules, interacting with interstitial 4,4'-bpy molecules (Fig. 2). The asymmetric unit comprises one copper(I) atom,
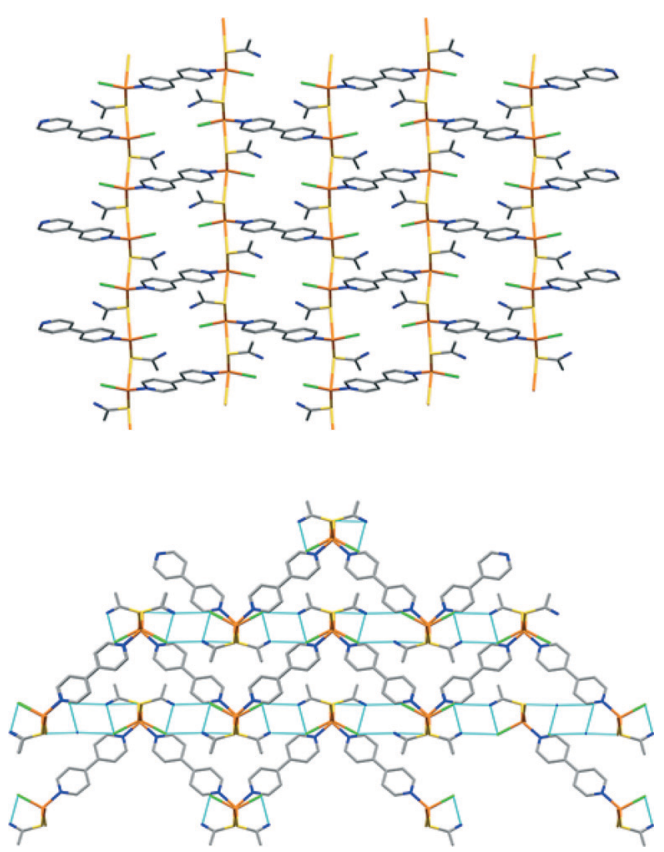

Fig. 1 View of a $\left[\mathrm{Cu}_{2} \mathrm{Cl}_{2}(\mathrm{TAA})_{2}\left(4,4^{\prime}-\text { bpy }\right)\right]_{n}$ layer in compound 1 (top) and packing of the layers with the inter- and intralayer hydrogen bonds shown in blue (bottom). In both representations hydrogen atoms have been omitted for clarity.

Table 3 Selected distances and angles for compounds 1-6

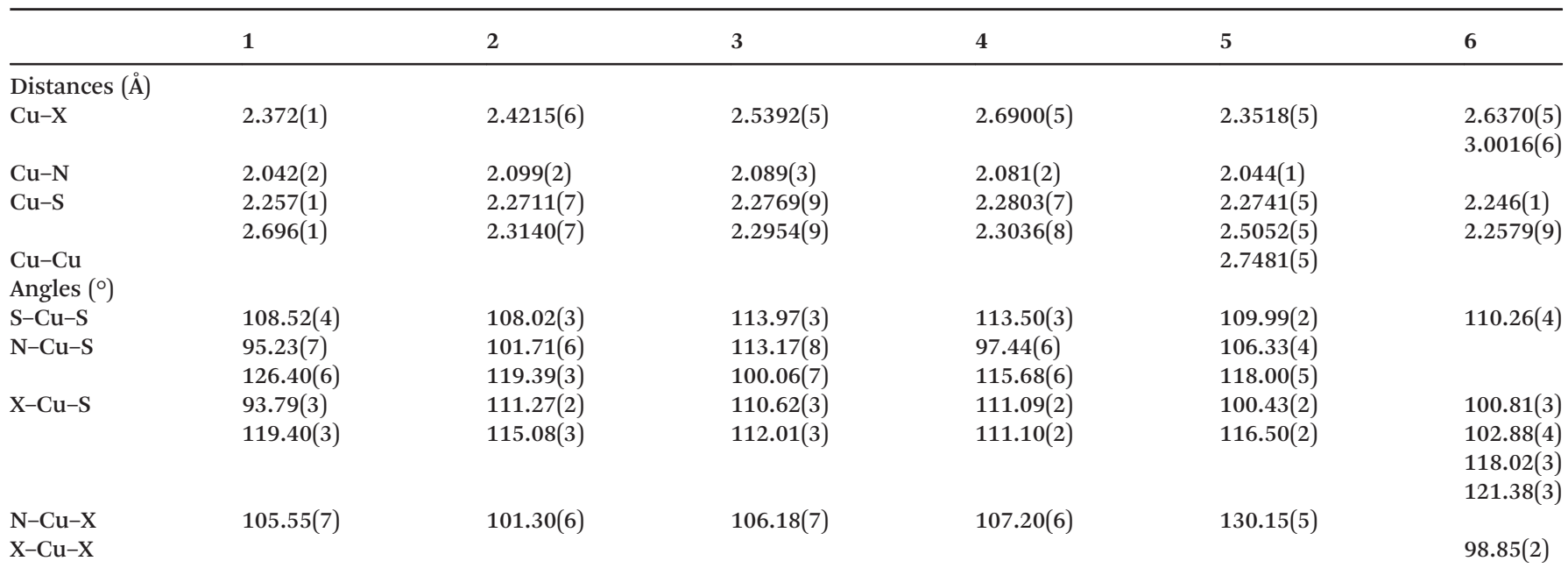


two TAA ligands, one half of a 4,4'-bpy coordinated molecule and another half of an interstitial free 4,4'-bpy. The coordination $\mathrm{CuS}_{2} \mathrm{ClN}$ environment of the copper atom displays a tetragonal geometry and consists of the chlorine atom, two sulphur atoms from the monotopic terminal TAA ligands and a nitrogen atom from a bridging $\mu_{2} 4,4^{\prime}$-bpy ligand.

The supramolecular network shows interactions between coordinated and free 4,4'-bpy ligands via $\mathrm{N}-\mathrm{H} \cdots \mathrm{N}$ hydrogen bonds between $\mathrm{NH}_{2}$ groups and nitrogen atoms from the pyridine rings (Fig. S14 $\dagger$ ), and $\pi-\pi$ stacking interactions between the pyridine rings (centroid distance $3.651 \AA$ ).

Compounds 3 and 4 , with formula [ $\mathrm{Cu}_{2} \mathrm{X}_{2}$ (TAA $)_{4}\left(4,4^{\prime}\right.$-bpy)] ( $\mathrm{X}=\mathrm{Br}, \mathrm{I}$ for 3 and 4 , respectively), are isostructural. Their crystal structures are very similar to that of compound 2 . Although both compounds crystallize in the monoclinic $C 2 / \mathrm{c}$ space group, these crystals also contain $\left[\mathrm{Cu}_{2} \mathrm{X}_{2}(\mathrm{TAA})_{4}\left(4,4^{\prime}-\right.\right.$ bpy)] dimeric molecules joined by hydrogen bonds and $\pi-\pi$ interactions to the interstitial 4,4'-bpy molecules (Fig. 3). The asymmetric unit contains one copper(I) atom, two TAA ligands, one half of a 4,4'-bpy coordinated molecule, and one half of a free 4,4'-bpy. The supramolecular network is defined by the $\mathrm{NH} \cdots \mathrm{X}(\mathrm{X}=\mathrm{Br}, \mathrm{I})$ and $\mathrm{N}-\mathrm{H} \cdots \mathrm{N}$ hydrogen bonds between the $\mathrm{NH}_{2}$ groups of the dimers and the free $4,4^{\prime}$-bpy molecules (Fig. S15 and S16 $\dagger$ ), and additional $\pi-\pi$ stacking interactions between rings of coordinated and free 4,4'-bpy (centroid distance of $3.629 \AA$ in 3 and 3.667 in 4). The two pyridine rings in the interstitial bipyridine molecules are not coplanar in this case, the same as those in compound 2, and display an angle of $34.79^{\circ}$ and $33.42^{\circ}$ for 3 and 4 , respectively.

Polymeric compound 5, with formula $\left[\mathrm{Cu}_{2} \mathrm{Cl}_{2}(\mathrm{TAA})_{2}(\mathrm{pyz})\right]_{n}$, crystallizes in the monoclinic $P 2_{1} / n$ space group with an asymmetric unit that contains one copper(I) atom, one TAA ligand, one chlorine atom and one half of a pyrazine ligand

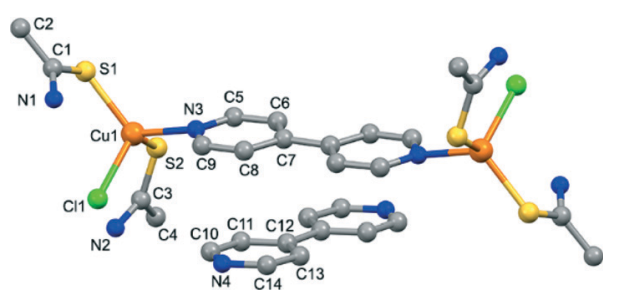

Fig. 2 View of the two types of molecules present in the crystal structure of 2, with labelled atoms in the asymmetric unit. Hydrogen atoms have been omitted for clarity.

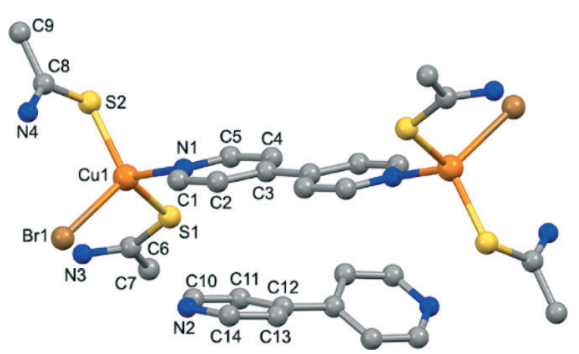

Fig. 3 View of the two types of molecules present in the crystal structure of 3, with labelled atoms in the asymmetric unit. Hydrogen atoms have been omitted for clarity.
(Fig. 4). It displays a one-dimensional coordination polymeric structure with the copper atoms in a $\mathrm{CuS}_{2} \mathrm{ClN}$ tetrahedral environment. Both the TAA and the pyz ligands are linking the copper atoms to form chains parallel to the [001] direction, with the halogen atoms acting as terminal ligands. Within the chains, two TAA molecules form a double bridge with the sulphur atoms joining the copper atoms located at $2.748 \AA$, and the pyrazine ligands also join two copper atoms $(\mathrm{Cu}-\mathrm{Cu}$ distance $4.839 \AA$ ) coordinating with the two opposite nitrogen atoms. The chains are packed in the crystal by the $\mathrm{N}-\mathrm{H} \cdots \mathrm{Cl}$ hydrogen bonds (Fig. S17†).

Compound 6 displays a dimeric $\left[\mathrm{Cu}_{2} \mathrm{I}_{2}(\mathrm{TAA})_{4}\right]$ molecular structure. It crystallizes in the triclinic $P \overline{1}$ space group with an asymmetric unit comprising one copper(I) centre, one TAA ligand and one iodine atom (Fig. 5). In this case, the TAA moieties do not act as bridging ligands but as terminal ones, and the iodine atoms are the ones that establish a double bridge between copper centres to yield the dimeric entity. The copper atoms are coordinated in a $\mathrm{CuS}_{2} \mathrm{I}_{2}$ tetrahedral
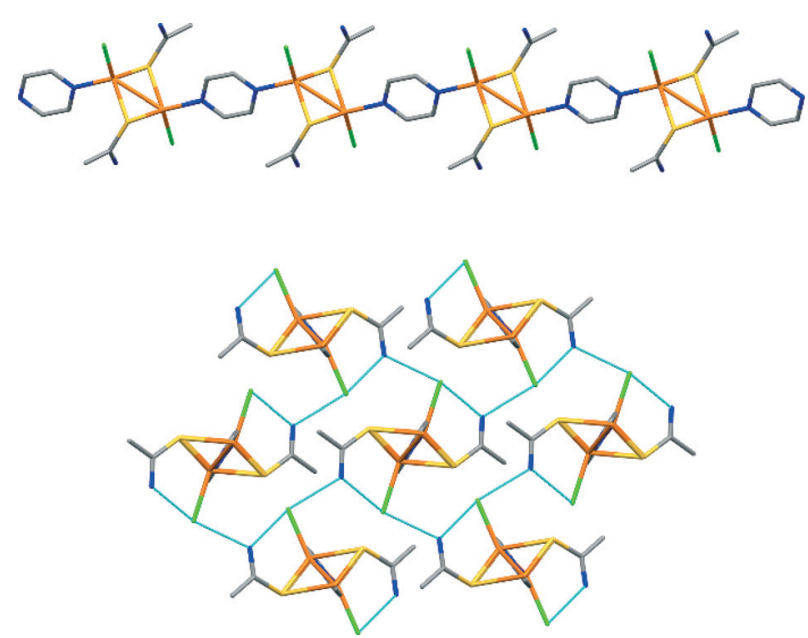

Fig. 4 View of a $\mathrm{Cu}_{2} \mathrm{Cl}_{2}(\mathrm{TAA})_{2}(\text { pyz) }]_{n}$ chain in compound 5 (top) and packing of the chains with inter- and intra-chain hydrogen bonds shown in blue (bottom). In both representations hydrogen atoms have been omitted for clarity.

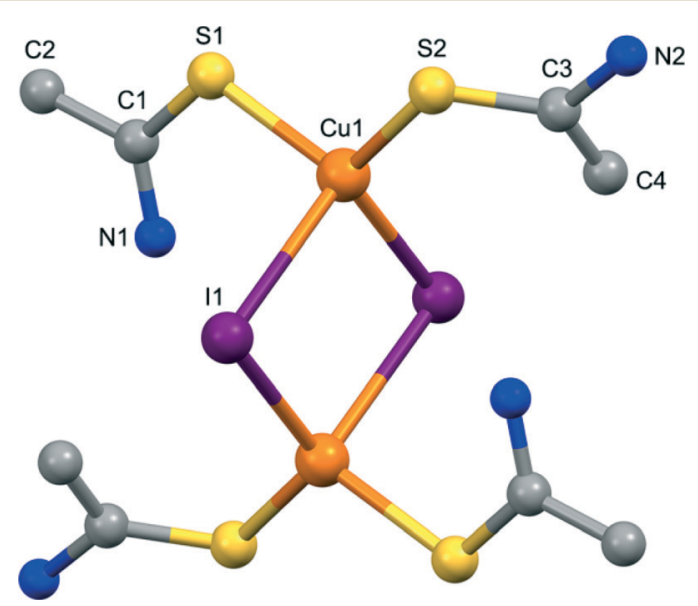

Fig. 5 View of the dimeric molecule in the crystal structure of 6, with labelled atoms in the asymmetric unit. Hydrogen atoms have been omitted for clarity. 
environment and located at a distance of $3.678 \AA$ A. The dimers are joined by the $\mathrm{N}-\mathrm{H} \cdots \mathrm{I}$ hydrogen bonds to form a dense net of supramolecular interactions (Fig. S18 $\dagger$ ).

\section{Photoluminescence properties}

Luminescent coordination polymers have recently undergone a great development due to their potential applications as light emitting diodes. ${ }^{52-57}$ Among these, CPs based on metal ions with a $\mathrm{d}^{10}$ electronic configuration ${ }^{58,59}$ and particularly those of $\mathrm{Cu}(\mathrm{I})$ are appropriate since they may show rich structural variety combined with bright luminescence emission varying from blue to red light. ${ }^{12}$ The solid-state luminescence properties of compounds 1-6 were investigated (solution studies were hindered by their insolubility). The mixedligand compounds 1-5 show strong orange-red luminescence that can be seen with the naked eye when they are excited with a UV lamp at $\lambda=365 \mathrm{~nm}$ (Fig. 6). The excitation of the solid samples at $\lambda=402 \mathrm{~nm}$ (at room temperature) produced a strong red-orange band emission with maximum values ranging from $589 \mathrm{~nm}$ for 1 up to $629 \mathrm{~nm}$ for 2 (Fig. 7). The determined values of the photoluminescence quantum yields $\left(\Phi_{\mathrm{PL}}\right)$ were $0.12,0.06,0.19,0.98$, and $1.55 \%$ for $1-5$, respectively. In the cases of coordination polymers 1 and 5, these values are similar to those found in other copper(I) halide based coordination networks. ${ }^{34}$ Generally, the electronic transitions responsible for the photoluminescence properties of copper(I) halide molecular and polymeric complexes with

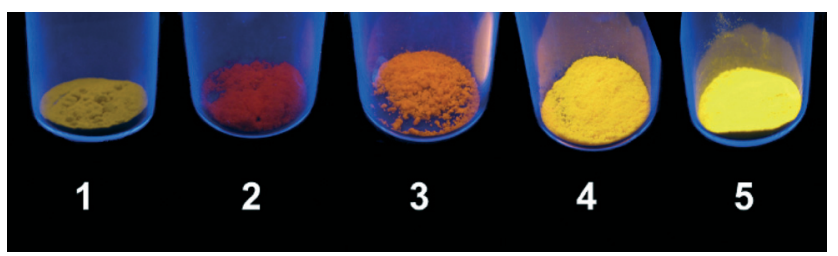

Fig. 6 Photographs of 1-5 under UV light $(\lambda=365 \mathrm{~nm})$.

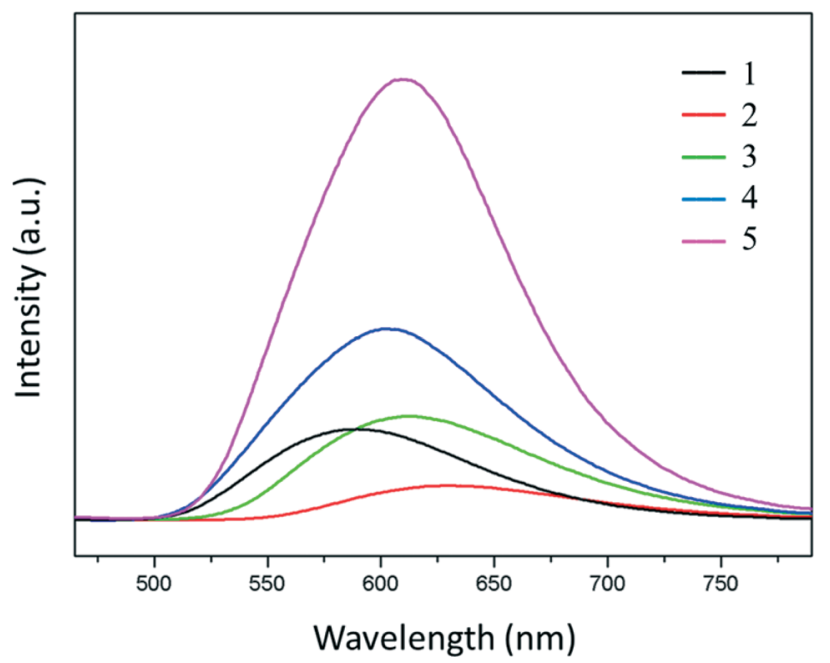

Fig. 7 Photoluminescence emission spectra of 1-5 in the solid state at $\lambda_{\mathrm{exc}}=402 \mathrm{~nm}$.
$\mathrm{N}$-donor ligands can be assigned to ligand-centered (LC), ligand-to-metal (LMCT) or metal to ligand charge transfers (MLCT) or metal-centered (MC) $d^{10} \rightarrow d^{9} s^{1}$. The presence of a halide atom in the complexes also enables the halide to metal charge transfer (XMCT). ${ }^{7,8}$ It has been already mentioned that 1-5 have a similar coordination environment where the metal center bonds to a terminal halide, an $\mathrm{N}$-donor ligand and two $\mathrm{S}$ atoms of two different thioacetamide ligands. Ligand-centered $\pi \rightarrow \pi^{*}$ transitions could be discarded because the thioacetamide as well as the $\mathrm{N}$-aromatic ligands (4,4'-bipy or pyz) shows weak photoluminescence in the blue region.

The metal-centered transition $\mathrm{d}^{10} \rightarrow \mathrm{d}^{9} \mathrm{~s}^{1}$ (MC) is only significant when the distance between the metal ions does not exceed the sum of the van der Waals radii (2.8 $\AA$ ) and this only takes place in compound $5[d(\mathrm{Cu}-\mathrm{Cu})=2.748 \AA]$. On the other hand, the similarities observed in the luminescence of compounds 1 and 5 ( $\lambda_{\mathrm{em}}=589$ and $609 \mathrm{~nm}$ for 1 and 5, respectively) suggest that although pyrazine has relatively different physical properties compared to those observed for 4,4'-bipyridine, a change of the ligand has no significant contribution in the luminescence indicating that the structure of the organic ligand does not play an important role in the luminescence behavior. However, the halide size seems to influence the emission maximum, because a decrease of the energy value is observed when the halide size increases $\left(\lambda_{\mathrm{em}}=629,613\right.$ and $604 \mathrm{~nm}$ for $2-4$, respectively) together with an increase in the $\mathrm{Cu}-\mathrm{X}$ distances $(2.42,2.54$ and $2.69 \AA$ for $2-4$, respectively). Taking into account the observation of the clear dependence between the $\mathrm{Cu}-\mathrm{X}$ distance and luminescence emission, we assume that XMCT is the dominating transition in all compounds. For 5, this XMCT transition is probably mixed with the contribution of metal-centered $\mathrm{d}^{10} \rightarrow$ $\mathrm{d}^{9} \mathrm{~s}^{1}$ (MC). The maximum emission values observed are similar to other [CuXN-donor] coordination polymers. ${ }^{34}$ Dimer 6 displays scarce luminescence in the blue region, showing a photoluminescence spectrum similar to thioacetamide (Fig. S19†), suggesting that these transitions could be assigned to ligandcentered $\pi \rightarrow \pi^{*}$ transitions and/or intraligand transitions.

\section{Electrical properties}

We have previously reported that $\mathrm{CPs}$ based on $\mathrm{Cu}(\mathrm{I})$ with organosulfur ligands are especially suitable to produce electrically conductive materials. ${ }^{4,60,61}$ Therefore, the structures of compounds 1 and 5 showing $\mathrm{S}$ atoms bridging metallic centres suggest their potential in terms of electrical conductivity. We have evaluated the electrical conductivity of single crystals of both compounds using the two-probe method at $300 \mathrm{~K}$.

For compound 1 , the electrical conductivity value of $1 \times$ $10^{-8} \mathrm{~S} \mathrm{~cm}^{-1}$ estimated from its $I-V$ curves suggests a semiconductor behaviour (Fig. S20 $\dagger$ ). However, compound 5 shows a very low electrical conductivity value of $c a .7 \times 10^{-12} \mathrm{~S} \mathrm{~cm}^{-1}$. Probably, this is a consequence of the crystal structure of 1 that shows $\mathrm{Cu}-\mathrm{S}-\mathrm{Cu}$ zigzag chains parallel to the $c$-axis, with short $\mathrm{Cu}-\mathrm{S}$ distances (2.257 and $2.696 \AA$, respectively) and connections between the $\mathrm{Cu}-\mathrm{S}-\mathrm{Cu}$ zigzag chains via the 
4,4'-bpy ligands (Cu-4,4'-bpy-Cu distance $11.252 \AA$ ). Taking this into account, the conductivity could probably be more favoured by the $\mathrm{Cu}-\mathrm{S}-\mathrm{Cu}$ pathway (Fig. 8a). In the case of 5 , the polymer chain is built from repeating $\mathrm{Cu}-\mathrm{Cu}-$ pyz units along the $c$ axis. Although the $\mathrm{Cu}-\mathrm{Cu}$ distance in the bimetallic units $(2.748 \AA)$ is slightly shorter than twice the van der Waals radius (1.40 $\mathrm{A})$, the longer distance between these bimetallic units joined by the pyrazine molecule $(6.883 \AA)$ can explain the non-conducting behaviour of 5 (Fig. 8b).

\section{Experimental}

\section{Materials and methods}

All the reagents were purchased from Sigma-Aldrich and used as received. FTIR spectra ( $\mathrm{KBr}$ pellets) were recorded on a Perkin-Elmer 1650 spectrophotometer. C, H, N, and S elemental analyses were performed at the Microanalysis Service of the Universidad Autónoma de Madrid on a Perkin-Elmer 240 B microanalyser. Powder X-ray diffraction experiments were carried out on a Diffractometer PANalytical X'Pert PRO theta/2theta primary monochromator and detector with fast $X$ 'Celerator. The samples have been analysed by scanning from theta to 2 theta. Direct current (DC) electrical conductivity measurements were performed on four different single crystals of compounds 1 and 5, connected with graphite paint to platinum wires ( $25 \mu \mathrm{m}$ diameter). The samples were measured at $300 \mathrm{~K}$ applying an electrical current with voltages from +10 to $-10 \mathrm{~V}$. Luminescence excitation and emission spectra of the solid compounds were recorded at $25^{\circ} \mathrm{C}$ on a $48000 \mathrm{~s}$ (T-Optics) spectrofluorometer from SLM-Aminco. A front face sample holder was used for data collection and

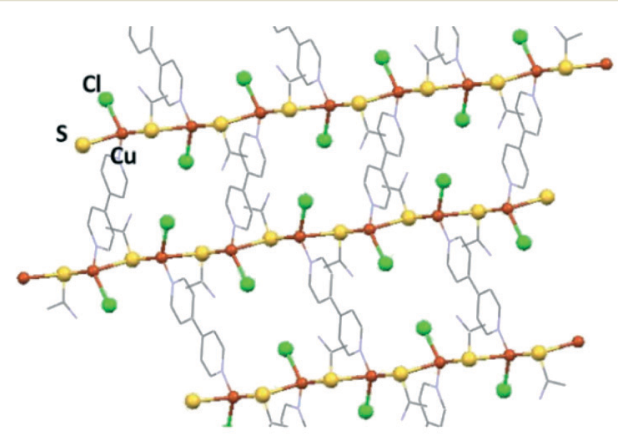

(a)

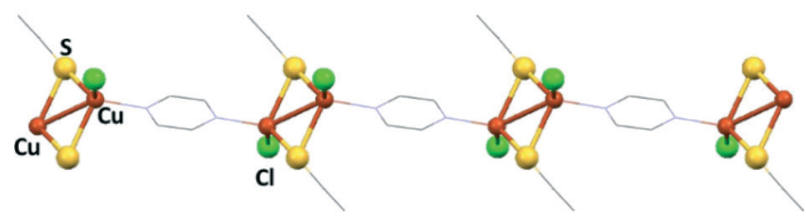

(b)

Fig. 8 (a) Representation of the possible pathway to the electrical conductivity across the $\mathrm{S}-\mathrm{Cu}-\mathrm{S}$ zigzag chains in compound 1. (b) Representation of the bimetallic $\mathrm{Cu}-\mathrm{S}-\mathrm{Cu}$ units, linked by pyrazine ligands to explain the insulator behaviour of compound $\mathbf{5}$. oriented at $60^{\circ}$ to minimize light scattering from the excitation beam on the cooled R-928 photomultiplier tube. Appropriate filters were used to eliminate Rayleigh and Raman scattering from the emission. The excitation and emission spectra were corrected for the wavelength dependence of the $450 \mathrm{~W}$ xenon arc excitation but not for the wavelength dependence of the detection system. UV-vis spectroscopic properties were determined by reflection (front face mode) on finely ground samples placed in quartz cells of $1 \mathrm{~mm}$ in path length. No attempt was made to remove adsorbed or dissolved molecular oxygen from the materials. Reference samples that do not contain any fluorescent dopant were used to check the background and optical properties of the samples. The overall quantum yields $(\Phi)$ were measured at r.t. using a method for powdered samples described by Bril et $a l .{ }^{62}$ The selected method involves the use of a standard phosphor (sodium salicylate) whose quantum yield at the excitation wavelength is estimated to be $60 \%$. The quantum yield is calculated by measuring the luminescence emission of the samples and the standard under the same conditions. To have absolute intensity values, diffuse reflectance of the samples and the standard was estimated.

\section{$\mathrm{X}$-ray data collection and crystal structure determination}

Data collection for compounds 1-6 were carried out in the Single Crystal X-Ray Diffraction Laboratory of SIdI (UAM) on a Bruker Kappa Apex II diffractometer, using graphitemonochromated Mo-K radiation $(\lambda=0.71073 \AA$ ) , operated at $50 \mathrm{kV}$ and $30 \mathrm{~mA}$. The cell parameters were determined and refined by a least-squares fit of all reflections. A semiempirical absorption correction (SADABS) was applied to all cases. The structures were solved by direct methods and refined by full-matrix least-squares procedures on $F^{2}$ (SHELXL97 (ref. 63)). All hydrogen atoms were included in their calculated positions and refined riding on the respective carbon atoms. Further crystallographic details for the structures reported here are collected in the ESI $\dagger$ and the files containing the deposited structures may be obtained from the Cambridge Crystallographic Data Center on quoting the depository numbers CCDC 1427905-1427910 (compounds 1-6, respectively).

\section{Synthetic procedures}

All the compounds were synthesized at room temperature under air atmosphere. The purity of the samples was checked by X-ray powder diffraction (Fig. S1-S6†).

Synthesis of $\left[\mathrm{Cu}_{2} \mathrm{Cl}_{2}(\mathrm{TAA})_{2}\left(4,4^{\prime}-\mathrm{bpy}\right)\right]_{n}$ (1). To a mixture of TAA $(0.114 \mathrm{~g}, 1.50 \mathrm{mmol})$ and 4,4'-bipyridine $(0.120 \mathrm{~g}, 0.75$ $\mathrm{mmol})$ in $10 \mathrm{~mL}$ of $\mathrm{MeCN}$, a solution of $\mathrm{CuCl}(0.150 \mathrm{~g}, 1.50$ $\mathrm{mmol}$ ) in $5 \mathrm{~mL}$ of MeCN was added and stirred for $10 \mathrm{~min}$ at $20{ }^{\circ} \mathrm{C}$. The resulting orange solid was collected by filtration, washed with MeCN and diethyl ether and dried in air. Yield: $0.272 \mathrm{~g}, 74 \%$ based on $\mathrm{Cu}$. The product was recrystallized from MeCN to afford suitable crystals for single-crystal X-ray diffraction measurements. Anal. calc. for $\mathrm{C}_{14} \mathrm{H}_{18} \mathrm{Cl}_{2} \mathrm{Cu}_{2} \mathrm{~N}_{4} \mathrm{~S}_{2}$ : 
C, 33.33; H, 3.60; N, 11.11; S, 12.71. Found: C, 33.34; H, 3.70; $\mathrm{N}, 11.21 ; \mathrm{S}, 12.51$. IR selected data (solid $\mathrm{KBr}$ pellet $v / \mathrm{cm}^{-1}$ ): 3194(s), 3016(s), 1646(m), 1601(s), 1531(m), 1506(m), 1482(s), 1404(s), 1359(s), 1319(m), 1216(m), 1066(m), 1042(m), 975(s), 799(s), $737(\mathrm{~m}), 724(\mathrm{~m}), 695(\mathrm{~s}), 632(\mathrm{~m})$.

Synthesis of $\left[\mathrm{Cu}_{2} \mathrm{Cl}_{2}(\mathrm{TAA})_{4}\left(4,4^{\prime}-\mathrm{bpy}\right)\right] \cdot\left(4,4^{\prime}-\mathrm{bpy}\right)$ (2). To a mixture of TAA $(0.152 \mathrm{~g}, 2.00 \mathrm{mmol})$ and 4,4'-bipyridine $(0.080 \mathrm{~g}, 0.50 \mathrm{mmol})$ in $15 \mathrm{~mL}$ of $\mathrm{MeCN}$ a solution of $\mathrm{CuCl}$ $(0.050 \mathrm{~g}, 0.50 \mathrm{mmol})$ in $15 \mathrm{~mL}$ of MeCN was added. After stirring for $10 \mathrm{~min}$ at $20{ }^{\circ} \mathrm{C}$, the reaction mixture was filtered through silica gel, then the volume was reduced under vacuum to $c a .2 \mathrm{~mL}$ and $10 \mathrm{~mL}$ of diethyl ether was added. The resulting orange crystals were collected by filtration, washed with diethyl ether and dried in air. Yield: $0.091 \mathrm{~g}, 45 \%$ based on Cu. Anal. calc. for $\mathrm{C}_{28} \mathrm{H}_{36} \mathrm{Cl}_{2} \mathrm{Cu}_{2} \mathrm{~N}_{8} \mathrm{~S}_{4}$ : C, 41.47; $\mathrm{H}, 4.47 ; \mathrm{N}$, 13.82; S, 15.82. Found: C, 41.49; H, 4.47; N, 13.77; S, 15.67. IR selected data (solid $\mathrm{KBr}$ pellet $\nu / \mathrm{cm}^{-1}$ ): 3268(s), 3099(s), 2923(m), 1636(m), 1598(s), 1532(m), 1486(m), 1457(w), 1408(s), 1367(w), 1311(m), 1218(w), 1062(w), 976(m), 816(m), 801(m), 711(s), 614(s).

Synthesis of $\left[\mathrm{Cu}_{2} \mathrm{Br}_{2}(\mathrm{TAA})_{4}\left(4,4^{\prime}-\mathrm{bpy}\right)\right] \cdot\left(4,4^{\prime}-\mathrm{bpy}\right)$ (3). Following the procedure similar to that used for 2 but using a 1 : $10: 1$ ratio of $\mathrm{CuBr}: \mathrm{TAA}: 4,4^{\prime}$-bpy, respectively, orange crystals were collected by filtration, washed with diethyl ether and dried in air. Yield: $0.119 \mathrm{~g}, 53 \%$ based on $\mathrm{Cu}$. Anal. calc. for $\mathrm{C}_{28} \mathrm{H}_{36} \mathrm{Br}_{2} \mathrm{Cu}_{2} \mathrm{~N}_{8} \mathrm{~S}_{4}$ : C, 37.37; H, 4.03; N, 12.45; S, 14.25. Found: C, 37.22; H, 4.05; N, 12.45; S, 14.17. IR selected bands (solid $\mathrm{KBr}$ pellet $\left.v / \mathrm{cm}^{-1}\right)$ : 3328(m), 3248(s), 3151(m), 1668(w), 1620(s), 1599(s), 1529(m), 1483(m), 1456(m), 1408(s), 1365(m), 1311(s), 1217(m), 1063(m), 978(m), 854(w), 806(s), 711(s), 613(s).

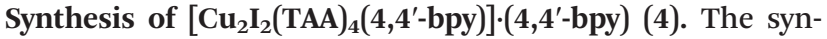
thetic conditions of compound 4 were analogous to 2 , but CuI $(0.096 \mathrm{~g}, 0.50 \mathrm{mmol})$ was used instead of $\mathrm{CuCl}$. Yield: $0.155 \mathrm{~g}, 62 \%$ based on $\mathrm{Cu}$. Anal. calc. for $\mathrm{C}_{28} \mathrm{H}_{36} \mathrm{I}_{2} \mathrm{Cu}_{2} \mathrm{~N}_{8} \mathrm{~S}_{4}$ : 33.84; H, 3.65; N, 11.28; S, 12.91. Found: C, 33.69; H, 3.66; N, 11.19; S, 12.80. IR selected bands (solid $\mathrm{KBr}$ pellet $v / \mathrm{cm}^{-1}$ ): 3298(m), 3248(s), 3150(m), 1661(w), 1615(s), 1596(s), 1527(m), 1482(m), 1452(m), 1404(s), 1361(m), 1301(s), 1216(m), 1062(m), 974(s), 852(w), 805(s), 708(s), 613(s).

Synthesis of $\left[\mathrm{Cu}_{2} \mathrm{Cl}_{2}(\mathrm{TAA})_{2}(\mathrm{pyz})\right]_{n}$ (5). To a mixture of TAA $(0.038 \mathrm{~g}, 0.50 \mathrm{mmol})$ and pyrazine $(0.405 \mathrm{~g}, 5.00 \mathrm{mmol})$ in 2 $\mathrm{mL}$ of $\mathrm{MeCN}$, a solution of $\mathrm{CuCl}(0.050 \mathrm{~g}, 0.50 \mathrm{mmol})$ in 3 $\mathrm{mL}$ of MeCN was added, and stirred for $10 \mathrm{~min}$ at $20^{\circ} \mathrm{C}$. The resulting orange solid was filtered, washed with EtOH and diethyl ether and dried in air. Yield: $0.068 \mathrm{~g}, 65 \%$ based on $\mathrm{Cu}$. Upon letting the filtered solution stand at $4{ }^{\circ} \mathrm{C}$ for three days, a few single crystals suitable for X-ray analysis formed. Anal. calc. for $\mathrm{C}_{8} \mathrm{H}_{14} \mathrm{Cl}_{2} \mathrm{Cu}_{2} \mathrm{~N}_{4} \mathrm{~S}_{2}$ : C, 22.43; H, 3.29; N, 13.08; S, 14.97. Found: C, 22.11; H, 3.33; N, 13.02; S, 14.99. IR selected bands (solid $\mathrm{KBr}$ pellet $v / \mathrm{cm}^{-1}$ ): 3152(m), 3030(s), 2968(s), $1667(\mathrm{~m}), \quad 1541(\mathrm{~m}), \quad 1480(\mathrm{~s}), \quad 1409(\mathrm{~s}), \quad 1373(\mathrm{~s}), \quad 1305(\mathrm{~m})$, 1276(w), 1157(m), 1117(w), 1053(w), 968(s), 801(m), 763(m), 692(s).

Synthesis of $\left[\mathrm{Cu}_{2} \mathrm{I}_{2}(\mathrm{TAA})_{4}\right]$ (6). A solution of CuI $(0.096 \mathrm{~g}$, $0.50 \mathrm{mmol}$ ) in $12 \mathrm{~mL}$ of MeCN was added to a solution of
TAA $(0.152 \mathrm{~g}, 2.00 \mathrm{mmol})$ in $3 \mathrm{~mL}$ of the same solvent. The mixture was stirred for $10 \mathrm{~min}$ at $20{ }^{\circ} \mathrm{C}$. The volume of the mixture was reduced under vacuum to $c a .1 \mathrm{~mL}$, and $10 \mathrm{~mL}$ of diethyl ether was added. The resulting white crystals were collected by filtration, washed with diethyl ether and dried in air. Yield: $0.310 \mathrm{~g}, 91 \%$ based on $\mathrm{Cu}$. Anal. calc. for $\mathrm{C}_{8} \mathrm{H}_{20} \mathrm{I}_{2} \mathrm{Cu}_{2} \mathrm{~N}_{4} \mathrm{~S}_{4}$ : C, 14.10; H, 2.96; N, 8.22; $\mathrm{S}, 18.82$. Found: C, 13.95; H, 2.88; N, 8.30; S, 18.29. IR selected bands (solid $\mathrm{KBr}$ pellet $\left.v / \mathrm{cm}^{-1}\right)$ : 3354(s), 3265(s), 3178(s), 1606(s), 1456(m), 1398(m), 1307(m), 970(m), 710(m), 573(m).

\section{Conclusions}

In this work we have investigated the reactivity of the ternary systems based on copper(I) halides (chloride, bromide and iodide), thioacetamide (TAA) and 4,4'-bipyridine (4,4'-bpy) or pyrazine (pyz), finding that the composition of the final products depends strongly on the halide, the $N, N^{\prime}$-ditopic ligand, and the stoichiometry employed. Hence, we have synthesized five new mixed ligand compounds, $1-5$, by changing the TAA : $\mathrm{N}$-donor ligand ratio, due to the competition between both of them. Moreover, solvent mediated transformations support the stoichiometric dependence on the construction of these solids. Due to the use of different N-heteroaromatic ligands and stoichiometries, various supramolecular architectures with different compositions were obtained, with structures ranging from discrete to one- and two-dimensional polymers. Mixed ligand compounds 1-5 display significant red solidstate luminescence emission upon irradiation with UV light at room temperature, where the halide atoms play a key role in the photoluminescence properties of these complexes. Additionally, electrical conductivity studies carried out on 1 and 5 suggest a semiconductor behaviour and an insulator behaviour, respectively. In summary, compound 1 represents an interesting multifunctional two-dimensional coordination polymer showing both significant red photoluminescence and moderate electrical conductivity.

\section{Acknowledgements}

We acknowledge financial support from MICINN (MAT201346753-C2-1-P). The authors are indebted to Dr. M. Zayat (ICCM-CSIC, Spain) for their assistance in luminescence measurements.

\section{References}

1 S. R. Batten, S. M. Neville and D. R. Turner, Coordination polymers: Design, analysis and application, Royal Society of Chemistry, 2009.

2 K. Hassanein, J. Conesa-Egea, S. Delgado, O. Castillo, S. Benmansour, J. I. Martínez, G. Abellán, C. J. Gómez-García, F. Zamora and P. Amo-Ochoa, Chem. - Eur. J., 2015, 17282-17292.

3 P. Amo-Ochoa, K. Hassanein, C. J. Gomez Garcia, S. Benmansour, J. Perles, O. Castillo, J. I. Martinez, O. Pilar and F. Zamora, Chem. Commun., 2015, 14306-14309. 
4 S. Delgado, P. J. Sanz Miguel, J. L. Priego, R. JiménezAparicio, C. J. Gómez-García and F. Zamora, Inorg. Chem., 2008, 47, 9128-9130.

5 A. Gallego, O. Castillo, C. J. Gomez-Garcia, F. Zamora and S. Delgado, Inorg. Chem., 2012, 51, 718-727.

6 A. Barbieri, G. Accorsi and N. Armaroli, Chem. Commun., 2008, 2185-2193.

7 P. C. Ford, E. Cariati and J. Bourassa, Chem. Rev., 1999, 99, 3625-3648.

8 V. Wing-Wah Yam and K. Kam-Wing Lo, Chem. Soc. Rev., 1999, 28, 323-334.

9 P. M. Graham, R. D. Pike, M. Sabat, R. D. Bailey and W. T. Pennington, Inorg. Chem., 2000, 39, 5121-5132.

10 A. J. Blake, N. R. Brooks, N. R. Champness, P. A. Cooke, M. Crew, A. M. Deveson, L. R. Hanton, P. Hubberstey, D. Fenske and M. Schröder, Cryst. Eng., 1999, 2, 181-195.

11 R. Peng, M. Li and D. Li, Coord. Chem. Rev., 2010, 254, 1-18.

12 H. Araki, K. Tsuge, Y. Sasaki, S. Ishizaka and N. Kitamura, Inorg. Chem., 2005, 44, 9667-9675.

13 I. Jess, P. Taborsky, J. Pospisil and C. Nather, Dalton Trans., 2007, 2263-2270.

14 J. Y. Lu, B. R. Cabrera, R.-J. Wang and J. Li, Inorg. Chem., 1999, 38, 4608-4611.

15 H. W. Roesky and M. Andruh, Coord. Chem. Rev., 2003, 236, 91-119.

16 K. Biradha, M. Sarkar and L. Rajput, Chem. Commun., 2006, 4169-4179.

17 S. R. Batten, J. C. Jeffery and M. D. Ward, Inorg. Chim. Acta, 1999, 292, 231-237.

18 H. Zhao, D. Jia, J. Li, G. J. Moxey and C. Zhang, Inorg. Chim. Acta, 2015, 432, 1-12.

19 H.-Y. Liu, H. Wu, J.-F. Ma, J. Yang and Y.-Y. Liu, Dalton Trans., 2009, 7957-7968.

20 H.-Q. Li, P. Wang, Y.-S. Ma, H.-J. Cheng, X.-Y. Tang, J.-M. Xie and R.-X. Yuan, Inorg. Chim. Acta, 2015, 429, 252-256.

21 S. Zhang, Z. Wang, H. Zhang, Y. Cao, Y. Sun, Y. Chen, C. Huang and X. Yu, Inorg. Chim. Acta, 2007, 360, 2704-2710.

22 M. Henary, J. L. Wootton, S. I. Khan and J. I. Zink, Inorg. Chem., 1997, 36, 796-801.

23 T. A. Tronic, K. E. deKrafft, M. J. Lim, A. N. Ley and R. D. Pike, Inorg. Chem., 2007, 46, 8897-8912.

24 Z. Li, J. Li and S. Du, J. Mol. Struct., 2006, 783, 116-121.

25 S. Zang, Y. Su, Y. Li, Z. Ni and Q. Meng, Inorg. Chem., 2005, 45, 174-180.

26 L. Xu, G.-C. Guo, B. Liu, M.-S. Wang and J.-S. Huang, Inorg. Chem. Commun., 2004, 7, 1145-1149.

27 R.-Z. Li, D. Li, X.-C. Huang, Z.-Y. Qi and X.-M. Chen, Inorg. Chem. Commun., 2003, 6, 1017-1019.

28 P. Gamez, P. d. Hoog, O. Roubeau, M. Lutz, W. L. Driessen, A. L. Spek and J. Reedijk, Chem. Commun., 2002, 1488-1489.

29 C. Shen, T. Sheng, C. Tian, Q. Zhu and X. Wu, Inorg. Chem. Commun., 2012, 17, 142-146.

30 B. F. Abrahams, S. R. Batten, H. Hamit, B. F. Hoskins and R. Robson, Angew. Chem., Int. Ed. Engl., 1996, 35, 1690-1692.
31 K. R. Kyle, C. K. Ryu, P. C. Ford and J. A. DiBenedetto, J. Am. Chem. Soc., 1991, 113, 2954-2965.

32 M. Vitale, W. E. Palke and P. C. Ford, J. Phys. Chem., 1992, 96, 8329-8336.

33 M. Vitale and P. C. Ford, Coord. Chem. Rev., 2001, 219-221, 3-16.

34 J. Pospisil, I. Jess, C. Nather, M. Necas and P. Taborsky, New J. Chem., 2011, 35, 861-864.

35 H.-B. Zhu and S.-H. Gou, Coord. Chem. Rev., 2011, 255, 318-338.

36 J. Troyano, J. Perles, P. Amo-Ochoa, J. I. Martinez, F. Zamora and S. Delgado, CrystEngComm, 2014, 16, 8224-8231.

37 M. Du, C.-P. Li, C.-S. Liu and S.-M. Fang, Coord. Chem. Rev., 2013, 257, 1282-1305.

38 Y.-Y. Yang, Z.-J. Lin, T.-T. Liu, J. Liang and R. Cao, CrystEngComm, 2015, 17, 1381-1388.

39 B.-Q. Ma, K. L. Mulfort and J. T. Hupp, Inorg. Chem., 2005, 44, 4912-4914.

40 H.-Y. Lin, J. Luan, X.-L. Wang, J.-W. Zhang, G.-C. Liu and A.-X. Tian, RSC Adv., 2014, 4, 62430-62445.

41 A. Gallego, O. Castillo, C. J. Gómez-García, F. Zamora and S. Delgado, Eur. J. Inorg. Chem., 2014, 2014, 3879-3887.

42 J. J. M. Amoore, L. R. Hanton and M. D. Spicer, Dalton Trans., 2003, 1056-1058.

43 Z.-M. Hao and X.-M. Zhang, Cryst. Growth Des., 2008, 8, 2359-2363.

44 L. R. Hanton and K. Lee, J. Chem. Soc., Dalton Trans., 2000, 1161-1166.

45 X.-C. Shan, F.-L. Jiang, D.-Q. Yuan, H.-B. Zhang, M.-Y. Wu, L. Chen, J. Wei, S.-Q. Zhang, J. Pan and M.-C. Hong, Chem. Sci., 2013, 4, 1484-1489.

46 M. Knorr, A. Bonnot, A. Lapprand, A. Khatyr, C. Strohmann, M. M. Kubicki, Y. Rousselin and P. D. Harvey, Inorg. Chem., 2015, 54, 4076-4093.

47 K. M. Henline, C. Wang, R. D. Pike, J. C. Ahern, B. Sousa, H. H. Patterson, A. T. Kerr and C. L. Cahill, Cryst. Growth Des., 2014, 14, 1449-1458.

48 F.-Y. Cui, K.-L. Huang, Y.-Q. Xu, Z.-G. Han, X. Liu, Y.-N. Chi and C.-W. Hu, CrystEngComm, 2009, 11, 2757-2769.

49 C. J. De Ranter and M. Rolies, Cryst. Struct. Commun., 1977, 6, 399-403.

50 N. S. Persky, J. M. Chow, K. A. Poschmann, N. N. Lacuesta, S. L. Stoll, S. G. Bott and S. Obrey, Inorg. Chem., 2000, 40, 29-35.

51 A. Goforth, M. Smith and H.-C. zur Loye, J. Chem. Crystallogr., 2003, 33, 303-306.

52 M. D. Allendorf, C. A. Bauer, R. K. Bhakta and R. J. T. Houk, Chem. Soc. Rev., 2009, 38, 1330-1352.

53 J. Heine and K. Muller-Buschbaum, Chem. Soc. Rev., 2013, 42, 9232-9242.

54 Y. Cui, Y. Yue, G. Qian and B. Chen, Chem. Rev., 2011, 112, 1126-1162.

55 E. Cariati, X. Bu and P. C. Ford, Chem. Mater., 2000, 12, 3385-3391.

56 D. M. Ciurtin, N. G. Pschirer, M. D. Smith, U. H. F. Bunz and H.-C. zur Loye, Chem. Mater., 2001, 13, 2743-2745. 
57 F. Wurthner and A. Sautter, Chem. Commun., 2000, 445-446.

58 V. W.-W. Yam and K. M.-C. Wong, Chem. Commun., 2011, 47, 11579-11592.

59 H. A. Habib, A. Hoffmann, H. A. Höppe, G. Steinfeld and C. Janiak, Inorg. Chem., 2009, 48, 2166-2180.

60 G. Givaja, P. Amo-Ochoa, C. J. Gomez-Garcia and F. Zamora, Chem. Soc. Rev., 2012, 41, 115-147.
61 S. S. Alexandre, J. M. Soler, P. J. Sanz Miguel, R. W. Nunes, F. Yndurain, J. Gómez-Herrero and F. Zamora, Appl. Phys. Lett., 2007, 90, 193107.

62 A. Bril and A. W. de Jager-Veenis, J. Electrochem. Soc., 1976, 123, 396-398.

63 G. M. Sheldrick, SHELXL-97, Program for Crystal Structure Refinement, Universität Göttingen, 1997. 